\title{
Testicular gamma glutamyl-transpeptidase: an index of Sertoli cell function in man
}

\author{
R. J. Sherins and G. D. Hodgen \\ Reproduction Research Branch, National Institute of Child Health and Human Development, \\ National Institutes of Health, Bethesda, Maryland 20014, U.S.A.
}

Many workers have studied testicular enzymes as specific markers of spermatogenesis (Bishop, 1968). However, the enzymes evaluated have primarily reflected the presence or absence of germ cells per se and have added little to our understanding of maturational events that was not already available by histological examination.

We have found that gamma glutamyl-transpeptidase may be a testicular marker of Sertoli cell function in the rat (Hodgen \& Sherins, 1973; Krueger, Hodgen \& Sherins, 1974). The specific activity of gamma glutamyl-transpeptidase increased markedly coincident with the cessation of Sertoli cell mitosis (Steinberger \& Steinberger, 1971) just before the onset of primary spermatocyte formation, and enzyme levels remained constant during the completion of spermatogenesis (Hodgen \& Sherins, 1973). In vitamin A-deficient rats, testicular levels of gamma glutamyl-transpeptidase were high, despite virtually complete germ cell depletion, although the activities of lactic dehydrogenase and sorbitol dehydrogenase fell in proportion to the reduced number of advanced germ cells.

To assess the relationship of gamma glutamyl-transpeptidase to the functional integrity of the seminiferous tubule in man, we have measured its concentration in homogenates made from testicular biopsies of normal and infertile men with a variety of disorders of spermatogenesis.

Eleven men were studied, and each subject was examined clinically to assess testicular function. Primary and secondary sexual development, presence of congenital somatic defects and testicular size (dimensions and volume) were evaluated. Three to five serial blood samples were obtained for measurements by radioimmunoassay of serum FSH (Cargille \& Rayford, 1970), LH (Odell, Ross \& Rayford, 1967) and testosterone (Nieschlag \& Loriaux, 1972). Sequential ejaculates were collected every other week for 6 months to determine sperm output. Semen was collected by masturbation after abstinence for $36 \mathrm{hr}$, in keeping with standard practice in our laboratory (Sherins, 1974).

A diagnostic testicular biopsy was performed under general anaesthesia only after all basal function studies were completed. A portion of the biopsy specimen was fixed in Bouin's fluid for routine histological processing and the remaining fresh tissue was immediately chilled to $4^{\circ} \mathrm{C}$, homogenized in phosphate-buffered saline and assayed for gamma glutamyl-transpeptidase activity as previously described (Hodgen \& Sherins, 1973).

The physical and biochemical characteristics of testicular function in these men are summarized in Table 1. Ten of the men were found to be normally masculinized and potent. The remaining man (S.G.) showed signs of sexual infantilism and anosmia, diagnostic of hypogonadotrophic hypogonadism; histologically the seminiferous tubules appeared similar to those of a 7-month human fetus (van Wagenen \& Simpson, 1965).

Three men (S.P., L.I. and G.C.) referred for infertility were considered to be normal after an extensive evaluation. One (S.P.) spontaneously impregnated his wife after these studies and the wives of the other two men were found to have inflammatory disease of the Fallopian tubes which would probably have precluded pregnancy.

Two subjects (R.H. and R.C.) with oligospermia showed maturation arrest at the spermatid level and two patients (W.W. and D.B.) with varicocoele had oligospermia associated with increased numbers of amorphous, tapered and immature cells (stress pattern) in the semen and qualitatively normal, but quantitatively reduced, numbers of germ cells in the biopsy specimen. Azoospermia, associated with germinal aplasia, was present in two additional subjects (J.D. and G.S.). A single oligospermic man (D.R.) had had surgical correction of unilateral cryptorchidism; testicular biopsy of the scrotal testis displayed peritubular thickening and reduced germ cell numbers. 


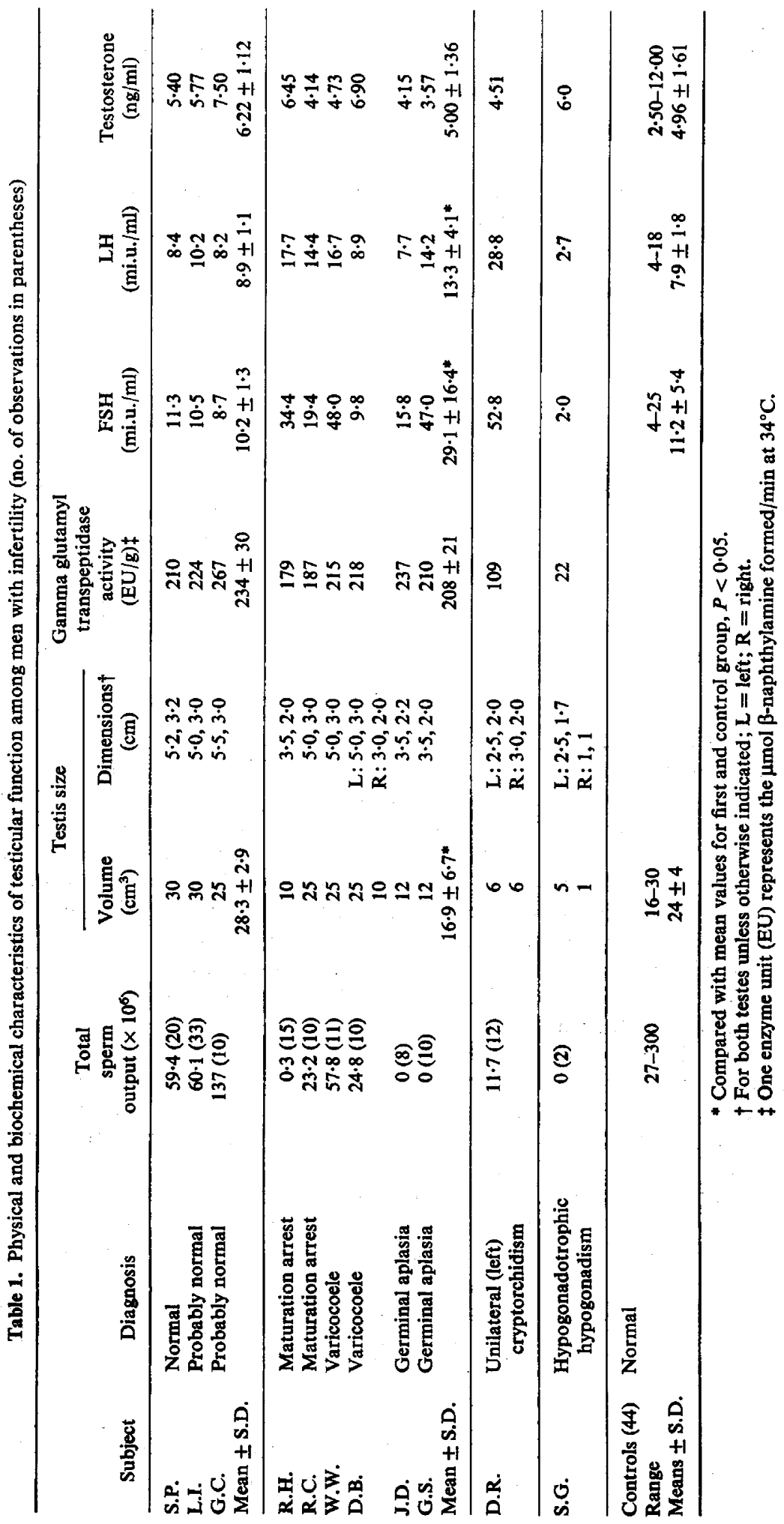


Serum FSH, LH and testosterone levels were indistinguishable from normal in the three men designated 'normal'. Among the 7 sexually mature men with disordered spermatogenesis, FSH concentrations were distinctly elevated in 4 (R.H., W.W., G.S. and D.R.), and the mean LH level for 7 men was significantly higher than that of the 'normal' and control men. Testosterone levels were within the normal range for all but the patient (S.G.) with hypogonadotrophic hypogonadism.

Testicular gamma glutamyl-transpeptidase activity among the normal men was indistinguishable $(P>0.2)$ from that found in 6 of the 7 men with testicular failure, despite marked differences in germ cell content which varied from complete absence (germinal aplasia) to quantitatively normal germ cell numbers and variable reciprocal changes in FSH concentration. In patient D.R., however, LH and FSH levels were increased and gamma glutamyl-transpeptidase was $50 \%$ less. The gamma glutamyl-transpeptidase activity in testis tissue from patient S.G. was approximately $10 \%$ that measured in the first 9 subjects.

Our study demonstrates that, in man, there is persistence of high testicular levels of gamma glutamyl-transpeptidase activity, despite germ cell depletion, and a low level of this enzyme when there is profound immaturity of seminiferous tubules and Sertoli cells. These results corroborate our earlier findings in the rat, and confirm that gamma glutamyl-transpeptidase activity is a useful marker of Sertoli cell maturation. In addition, however, the finding of reduced enzyme activity in a man with cryptorchidism and compensated Leydig cell failure suggests that gamma glutamyltranspeptidase may be regulated by intratesticular levels of androgen.

To our knowledge, this is the first evidence of an enzyme marker of Sertoli cell function in man. Although our data do not allow us to define the physiological control mechanisms for gamma glutamyl-transpeptidase activity, it is interesting to speculate that this enzyme may be androgendependent.

We thank Mr Charles Turner and Mr David Brightwell for their technical contributions.

\section{References}

Bishop, D.W. (1968) Testicular enzymes as fingerprints in the study of spermatogenesis. In Perspectives in Reproduction and Sexual Behavior, pp. 261-286. Ed. M. Diamond. Indiana University Press, Bloomington and London.

Cargille, C.M. \& Rayford, P.L. (1970) Characterization of antisera for human follicle-stimulating hormone radioimmunoassay. J. Lab. clin. Med. 75, 1030-1040.

Hodgen, G.D. \& Sherins, R.J. (1973) Enzymes as markers of testicular growth and development in the rat. Endocrinology 93, 985-989.

Krueger, P.M., Hodgen, G.D. \& Sherins, R.J. (1974) New evidence for the role of the Sertoli cell and spermatogonia in feedback control of FSH secretion in male rats. Endocrinology 95, 955-962.

Nieschlag, E. \& LoRIAUX, D.L. (1972) Radioimmunoassay for plasma testosterone. $Z$. Klin. Chem. Klin. Biochem. 10, 164-168.
Odell, W.D., Ross, G.T. \& RAYFord, P.L. (1967) Radioimmunoassay for LH in human plasma or serum. J. clin. Invest. 46, 248-255.

SHERINS, R.J. (1974) Clinical aspects of treatment of male infertility with gonadotropins: testicular. response of some men given hCG with and without pergonal. In Proceedings of the Serono Symposium on Male Fertility and Sterility, Vol. 5, pp. 545-565. Eds R.E. Mancini \& L. Martini. Academic Press, New York.

Steinberger, A. \& Steinberger, E. (1971) Repiication pattern of Sertoli cells in maturing rat testis in vivo and in organ culture. Biol. Reprod. 4, 84-87.

VAN WAGENEN, G. \& SiMPSON, M.E. (1965). Embryology of the ovary and testis: Homo sapiens and Macaca mulatta. Yale University Press, New Haven and London. 